\title{
INTERNET NA BIBLIOTECA ESCOLAR: BLOG BIBLIOTECA ETS: CRIAÇÃO E EVOLUÇÃO DESTA FERRAMENTA DA WEB 2.0
}

Kátia Soares Coutinho, Eliane Lourdes da Silva Moro, Lizandra Brasil Estabel katias coutinho@hotmail.com, eliane moro@yahoo.com.br, lizandra.estabel@poa.ifrs.edu.br

\author{
Escola Estadual Técnica em Saúde no HCPA (ETS) \\ Faculdade de Biblioteconomia e Comunicação (FABICO/UFRGS) \\ Instituto Federal do Rio Grande do Sul - Campus Porto Alegre (IFRS)
}

\begin{abstract}
Resumo. Mostra a utilização das Tecnologias de Informação e de Comunicação (TICs) na biblioteca escolar. Detalha os elementos internos que constituem o Blog da Biblioteca da Escola Estadual Técnica em Saúde, no Hospital de Clínicas de Porto Alegre (ETS), localizada na cidade de Porto Alegre, RS, criado por exigência do Curso de Especialização em Bibliotecas Escolares e Acessibilidade (EBEA/UFRGS em EAD, mediada por computador). Este estudo se caracteriza como uma pesquisa qualitativa e investiga como o blog Biblioteca ETS, contribui na relação entre a biblioteca e a comunidade escolar, através da analise dos 500 primeiros posts desta ferramenta da Web 2.0 e mostra as interações com a comunidade escolar e outros internautas.
\end{abstract}

Palavras-chave: Bibliotecas escolares. Blogs. Web 2.0. TIC.

\begin{abstract}
It shows the use of Information and Communication Technologies (ICTs) in school library. It details the intern elements that constitute the Library's Blog of State School Technical in Health, at Porto Alegre Clinical Hospital, located in Porto Alegre, RS, created in requirement by School Libraries and Accessibility Specialization Course (UFRGS/ Open and Distance Education). It analyzes the first 500 posts of this Web 2.0 tool. It shows interactions with school community and other Net surfing people.

Keywords: Blogs. School libraries. Web 2.0. Information and Communication Technologies.
\end{abstract}

\section{INTRODUÇÃO}

Neste século, as Tecnologias de Informação e de Comunicação (TICS), com sua enorme quantidade de dados e a possibilidade de interação e rápida recuperação de documentos, vieram revolucionar e transformar todos os setores da sociedade, inclusive os saberes advindos da educação formal.

A velocidade com que as TICs avançam e se aperfeiçoam é extraordinária e "para os 'nativos digitais'1, a educação se encontra intimamente associada ao emprego de avançadas tecnologias de informação e de comunicação, e a Internet representa para eles um natural ambiente de aprendizagem." (ROSA, 2009, p.174).

A educação precisa apropriar-se destas novas formas de comunicação e de acesso à informação de modo a facilitar a entrada do educando na Sociedade do Conhecimento e da Aprendizagem no mundo do trabalho. Novas habilidades e competências são requeridas para que isto se 
concretize, pois mais do que 'treinamento', tem que haver mudanças estruturais e filosóficas no sistema educacional vigente.

Este artigo apresenta o estudo do processo de criação e manutenção de um blog de biblioteca de escola técnica estadual em Porto Alegre/RS, como uma atividade do Curso de Especialização em Bibliotecas Escolares e Acessibilidade (EBEA) na modalidade EAD, mediada por computador, realizado pela FABICO/UFRGS, intitulado: Blog Biblioteca ETS criado em setembro de 2008.

Nesta perspectiva, a pergunta de investigação consiste em: como o blog "Biblioteca ETS" (ferramenta da Web 2.0) contribuiu na relação entre a biblioteca e a comunidade de Porto Alegre/RS? Como objetivo geral o estudo pretende verificar como o blog "Biblioteca ETS" contribui na relação entre a biblioteca e a comunidade. Para tal, procura-se identificar o uso do blog "Biblioteca ETS" como fonte de informação; auxiliar na promoção de inclusão digital e laboral, capacitando os membros da comunidade escolar no uso de ferramentas da Web 2.0; analisar as interações entre a biblioteca e a comunidade proporcionadas pelo blog; verificar, através de interação com a comunidade escolar, se a ferramenta criada atende às expectativas de seus leitores.

Com a análise interna do objeto em estudo (os elementos que constituem o blog Biblioteca ETS), espera-se aprimorar ainda mais esta ferramenta de modo a buscar maior interação e proximidade com a comunidade escolar.

\section{WEB 2.0 E A BIBLIOTECA ESCOLAR}

Localizada na capital gaúcha, junto ao Hospital de Clínicas de Porto Alegre (HCPA), a Escola Estadual Técnica em Saúde (ETS) possui atualmente cerca de 800 alunos matriculados, 73 professores regentes de classe e 18 supervisores educacionais e funcionários, com aulas nos três turnos. Oferece quatro cursos técnicos, desde a sua criação em março de 1991: Administração Hospitalar; Radiologia e Radiodiagnóstico; Patologia Clínica e Nutrição e Dietética.

A biblioteca escolar deve procurar integrar-se ao programa pedagógico da escola, fornecendo subsídios informacionais para os conteúdos trabalhados em aula, colaborando com os professores, visando melhorar as condições e a realidade que se tem para tornar mais prazerosa a estadia de quem busca informação e mais frequente a procura pelos serviços ali oferecidos.

O profissional responsável por dinamizar a biblioteca escolar, ao interagir com as pessoas, procurando suprir suas necessidades informacionais, deve ter sempre em vista a função educativa do setor bem como a colaboração com seus colegas docentes - e a participação em reuniões pedagógicas é um valioso espaço para que isto se efetive - também deve buscar aprimoramento e qualificação profissional constante. Interação com a equipe diretiva e com os setores de apoio da escola são fundamentais para que o serviço possa fluir de modo seguro rumo aos objetivos que se quer alcançar (NEVES, 2004).

Assim, parafraseando o jornalista e blogueiro Ricardo Noblat ${ }^{2}$ que afirma que "a missão de um jornalista é informar", pode-se inferir que o mesmo se aplica ao profissional da informação - esteja ele na biblioteca escolar, 
pública, universitária ou especializada - acreditando-se que a missão de um bibliotecário é disponibilizar, mediar e disseminar a informação, seja em que suporte se apresente. Os blogs são excelentes fontes de informação, leitura, atualização, lazer e interação entre as pessoas podendo tornar-se ferramentas úteis em quaisquer bibliotecas, especialmente entre as escolares, por seu caráter colaborativo, a ludicidade presente desde o nome onomatopéico, a facilidade de criação e manutenção e a grande quantidade de assuntos existentes na blogosfera, onde os edublogs (blogs educativos) despontam com ótimas reflexões acerca do fazer pedagógico³.

Ações envolvendo conceitos de marketing e a divulgação de campanhas, endereço do blog/site, acervo recebido e outras devem ser feitas de modo constante, devido à rotatividade tanto dos alunos que só permanecem nas aulas teóricas durante três semestres, quanto do corpo docente e funcionários.

Por outro lado, o acesso às TICs facilita a recuperação da informação e abre novas possibilidades de obtenção de renda, acesso ao mundo do trabalho, facilidade de se comunicar e de buscar a educação durante toda a vida. No entanto, devemos lembrar-nos que o desafio para a inclusão digital/informacional "[. . . .] inicia-se pela dependência de infraestrutura tecnológica e de sua manutenção, mas, sobretudo, da capacidade de se extrair conteúdo dos aparatos técnicos, transformando-os em conhecimento." (AUN; ANGELO, 2007, p. 66-67). Ou seja, transformando as informações e conhecimentos obtidos através das TICs em aplicações práticas para a vida quotidiana e laboral do aluno cidadão.

Assim, o bibliotecário tem o dever de orientar seus usuários na utilização destas tecnologias e, sempre que possível, interagir com os professores, disponibilizando links úteis para os alunos, mantendo um intercâmbio sobre atividades e novos conhecimentos na área, procurando novidades e sugerindo melhorias para a instituição; incentivar os colegas docentes e funcionários que apresentam dificuldades com as ferramentas digitais; sugerir outras formas de recuperar as informações e novos caminhos semânticos aos alunos que desconhecem certos recursos. Além disso, "o bibliotecário tem a função de gestor e de educador, buscando a oferta de serviços, através da avaliação no uso de ferramentas de gestão, e qualidade, propiciando o acesso e o uso da informação para todos". (BEHR, MORO, ESTABEL, 2008, p.32). Na prática diária em biblioteca escolar de instituição técnica, constatam-se as dificuldades de busca da informação pertinente, para atender as necessidades de busca da comunidade escolar que a biblioteca atende.

\section{METODOLOGIA}

Este estudo se caracteriza como pesquisa qualitativa e pretende investigar como o blog Biblioteca ETS, ferramenta da Web 2.0, contribuiu na relação entre a biblioteca e a comunidade escolar. Como instrumento para a coleta de dados foi utilizada a análise documental através dos elementos internos que constituem o blog Biblioteca ETS (figura 1), coleta de depoimentos orais espontâneos, correspondência em diferentes ambientes virtuais, materiais e/ou comentários enviado pelos leitores do blog, observação das interações e das repercussões ocorridas tanto no ambiente escolar como fora da instituição 
tais como: citação em eventos diversos e também no Jornal Correio do Povo de Porto Alegre, RS; participação no Prêmio Top Blog - classificação no Top 100, Categoria Variedades, Particular (promoção nacional do Portal Top Blog).

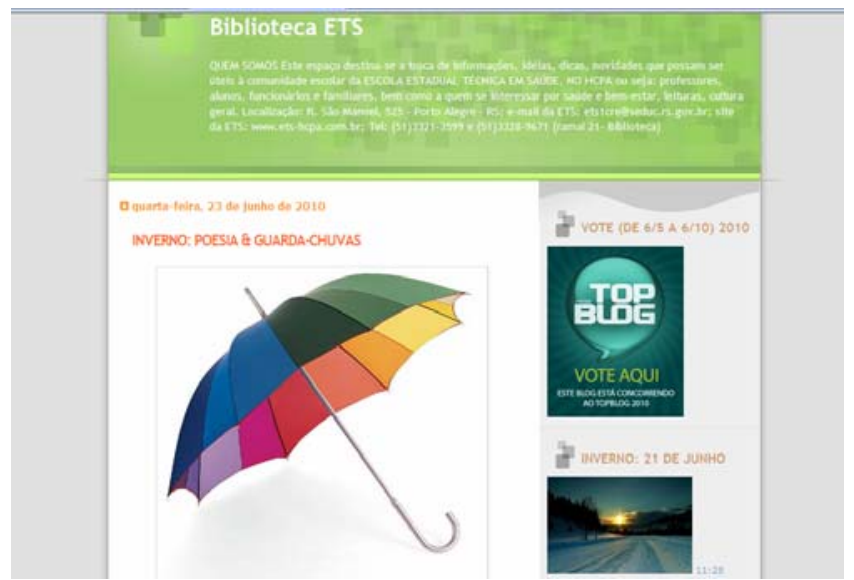

Figura 1: BLOG da Biblioteca ETS

Os cinco instrumentos a seguir foram construídos levando-se em conta os primeiros 500 posts - desde a criação do blog Biblioteca ETS, no período de setembro de 2008 a novembro de 2009, considerados como o universo a ser analisado.

Procurou-se responder a diversas questões referentes ao processo de criação e desenvolvimento da ferramenta Web 2.0 quanto aos seus elementos internos (links, comentários/interação com os leitores, assuntos, tags, divulgação de ações da Instituição e/ou da Biblioteca, entre outros). Desta maneira foi possível verificar as interações propiciadas pelo blog e os usuários da Biblioteca da ETS. A seguir algumas considerações sobre cada item dos quadros (1 e 2) abaixo:

a) datas (dias): refere-se a cada post publicado no blog;

b) títulos: cada post individual publicado no blog;

c) Curso EBEA: o blog surgiu como uma atividade do Curso, portanto há muitas referências ao mesmo até o seu encerramento;

d) referência à Biblioteca ou ETS: citações explícitas a respeito de: outros eventos (out.) na biblioteca/promovidos pela ETS $\left(1^{\mathrm{a}}\right.$ coluna), obra e demais materiais bibliográficos do acervo $\left(2^{\mathrm{a}}\right.$ coluna) ainda que em outros locais (o HCPA sedia a maioria dos mesmos);

e) imagens (I): o objetivo é quantificar a média de imagens utilizadas em cada post;

f) links ou referências: pode-se ter a média de links por post e ver a divulgação total de outros endereços eletrônicos ou informações referenciadas;

g) referências (Ref. a outros posts do blog): posts que remetem a informações de outros posts, podendo ampliar o entendimento do leitor;

h) comentários (Com.): feitos pelos internautas visitantes e/ou pela blogueira, respondendo/agradecendo as colocações feitas;

i) rascunhos $(R)$ : material não publicado: 


\begin{tabular}{|c|c|c|c|c|c|c|c|c|c|}
\hline $\begin{array}{l}\text { Datas } \\
\text { (dias) }\end{array}$ & Tít. & $\begin{array}{l}\text { Curso } \\
\text { EBEA }\end{array}$ & & $\begin{array}{l}\text { à Bib. } \\
\text { ETS: } \\
88\end{array}$ & I & $\begin{array}{c}\text { Links } \\
\text { ou } \\
\text { refer. } \\
\text { fora da } \\
\text { ETS }\end{array}$ & $\begin{array}{c}\text { Ref. a } \\
\text { outros } \\
\text { posts } \\
\text { do } \\
\text { blog }\end{array}$ & Com. & $\mathbf{R}$ \\
\hline & & & Out. & ETS/Bib & & & & & \\
\hline 291 & 371 & 22 & 51 & 37 & 722 & 782 & 50 & 128 & 72 \\
\hline
\end{tabular}

Quadro 1 - Geral: Primeiros 500 Posts do Blog Biblioteca ETS (sem as biografias).

Os posts referentes a dados biográficos de escritores, artistas, músicos e outros, por serem diferenciados, mereceram um quadro especial (Quadro 2), onde foram acrescentados outros dados como sua profissão (Profissão/Assunto) e a nacionalidade, subdividindo-se este item em: $\mathbf{E}$ (estrangeiro), B (brasileiro) e RS (para os gaúchos); Nos casos em que há biografias de diversas pessoas no mesmo post, considerou-se apenas 0 primeiro biografado e a respectiva profissão. Os demais itens permanecem os mesmos, com exceção de uma coluna ("Curso EBEA"); Referência à Biblioteca elou ETS (através de Obra referenciada existente no acervo primeira coluna). Se não há referência (Outr.) o post traz assunto - biografia de pessoa - que não existe em nosso acervo para empréstimo, somente em obras de referência tais como enciclopédias; Imagem; Links fora da ETS; Refer. a outros posts deste blog; Comentários (Com.) tanto de leitores como da blogueira; Rascunhos (R):

\begin{tabular}{|c|c|c|c|c|c|c|c|c|c|}
\hline Datas & $\begin{array}{l}\text { Profissão } \\
\text { IAssunto }\end{array}$ & $\begin{array}{c}\mathbf{N} \\
\mathbf{a} \\
\mathrm{c} \\
\mathrm{i} \\
\mathrm{o} \\
\mathrm{n} .\end{array}$ & \multicolumn{2}{|c|}{$\begin{array}{c}\text { Referência } \\
\text { à } \\
\text { Biblioteca } \\
\text { elou ETS }\end{array}$} & $\begin{array}{l}\text { I } \\
\text { m } \\
\mathbf{a} \\
\mathbf{g} \\
\mathrm{e} \\
\mathrm{m}\end{array}$ & $\begin{array}{c}\text { Links } \\
\text { fora } \\
\text { da } \\
\text { ETS }\end{array}$ & $\begin{array}{c}\text { Refer. } \\
\text { a } \\
\text { outros } \\
\text { posts } \\
\text { deste } \\
\text { blog }\end{array}$ & Com. & $\mathbf{R}$ \\
\hline \multirow[t]{4}{*}{$\begin{array}{c}\text { Total: } \\
57\end{array}$} & $\begin{array}{l}\text { Escritorl } \\
\text { poeta: } 22\end{array}$ & $\mathrm{E}: 27$ & $\begin{array}{c}\text { Obra } \\
55\end{array}$ & $\begin{array}{c}\text { Outr. } \\
1\end{array}$ & 158 & 230 & 8 & 16 & 0 \\
\hline & $\begin{array}{c}\text { Art. } \\
\text { plást.: } 8\end{array}$ & B: 24 & & & & & & & \\
\hline & $\begin{array}{l}\text { Músico/ } \\
\text { cantor: } 8\end{array}$ & RS: 6 & & & & & & & \\
\hline & Vários:13 & $\begin{array}{c}\mathrm{T}: \\
57\end{array}$ & & & & & & & \\
\hline
\end{tabular}

Quadro 2 - Específico: Posts de Dados Biográficos do Blog Biblioteca ETS. 
O terceiro instrumento é um gráfico onde estão representados os assuntos dos 500 posts analisados. O critério usado foi a atribuição de um assunto a cada post, independente da(s) tag(s) já utilizadas. A categoria "vários" foi utilizada para englobar aqueles posts que abrangem mais de um assunto. Foram reagrupados e levados em conta os posts referentes a dados biográficos de personalidades, sendo o assunto considerado o seu métier, por exemplo, Darwin - Profissão: cientista/assunto: ciência. Os eventos promovidos pela escola ou dentro da biblioteca encontram-se sob o assunto "BIB/ETS".

Os dez assuntos mais repetidos verificados nos 500 posts do blog são apresentados na figura 2.

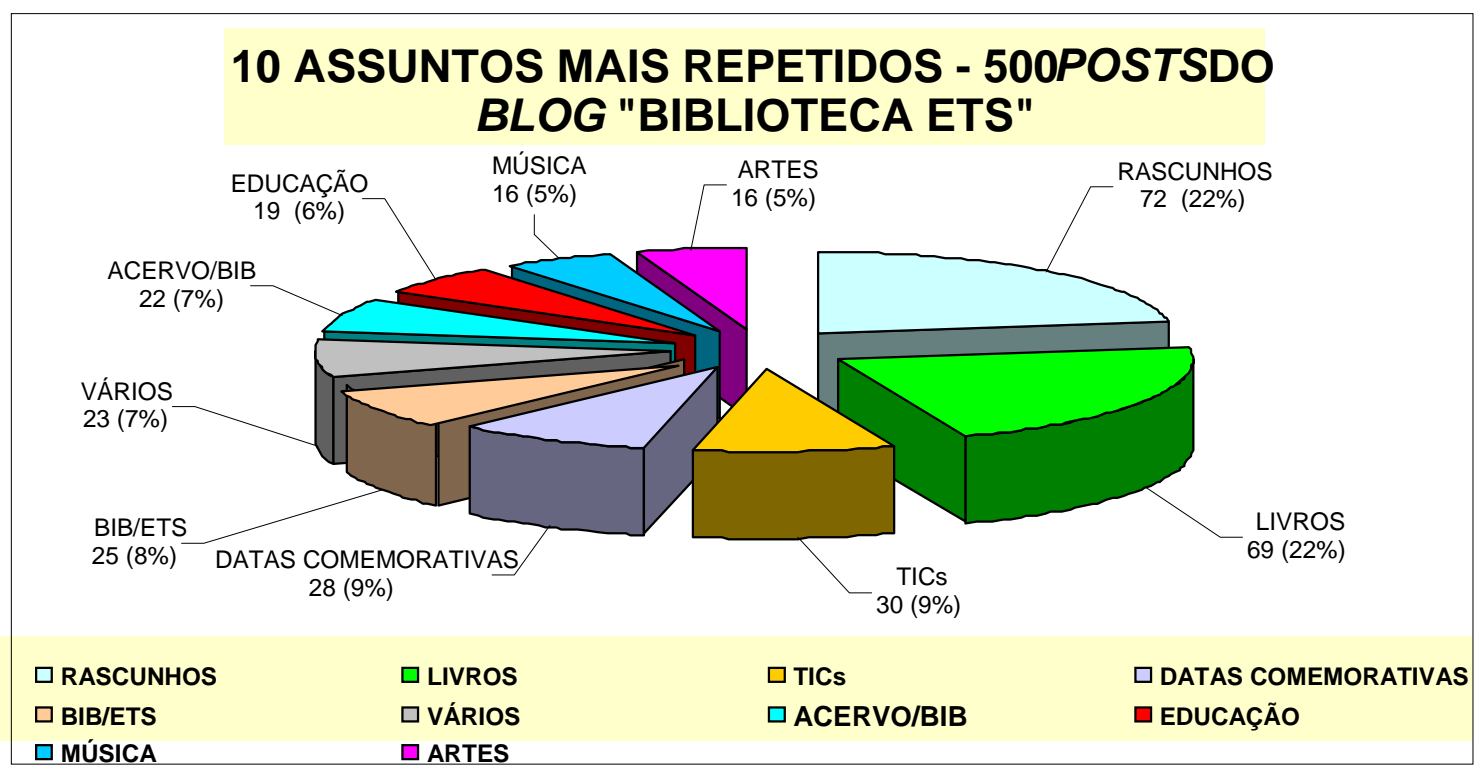

Figura 2 - 10 Assuntos Mais Repetidos nos 500 Posts do blog.

O quarto instrumento é um gráfico (Figura 3) cujas informações partiram das oitocentos e quatro tags utilizadas no blog e a frequência com que as mesmas aparecem nos posts. Foi feito um recorte considerando-se as dez tags com maior número de aparições no período focalizado: 


\section{TAGS DO BLOG "BIBLIOTECA ETS"}

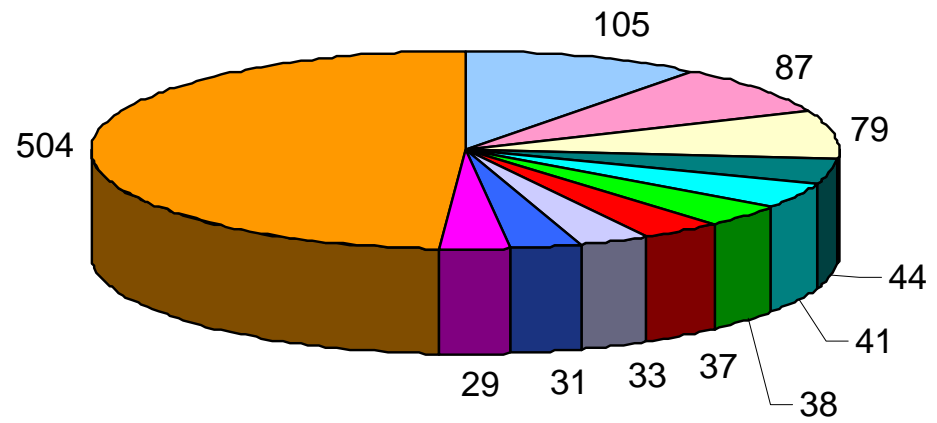

\section{$\square$ LEITURA}

口DATAS COMEMORATIVAS

口PORTO ALEGRE

$\square$ ETS

口 LITERATURA

TAGS QUE APARECEM UMA VEZ

\section{$\square$ EVENTO}

$\square$ LIVROS

$\square$ ARTE

$\square$ LIVRO

$\square$ COMUNICAÇÃO

Figura 3 - 10 tags mais Frequentes e o Número de Tags Utilizadas Somente Uma Vez (frequência total: 1028 citações)

Finalmente, para saber a quantidade de posts que menciona diretamente a biblioteca ou a ETS, divulgando eventos, exposições, trabalhos dos alunos e outros e o percentual de notícias que se referem especificamente ao acervo existente na Biblioteca da ETS, bem como mostras de trabalhos de diversas disciplinas, construiu-se um último gráfico (Figura 4), onde aparece em primeiro lugar a expressiva quantidade de 334 posts que não mencionam nem a biblioteca, nem a escola, ou seja, tratam de assuntos - os mais diversos - alheios ao universo da escola/biblioteca:

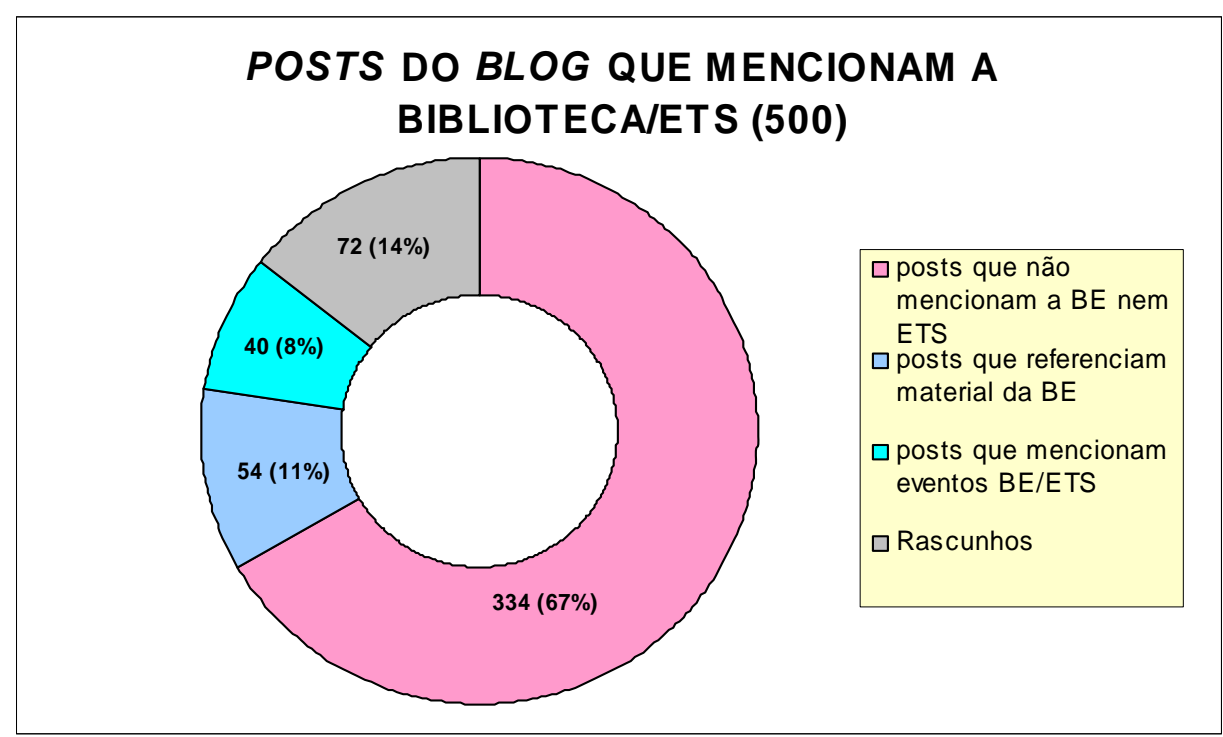

Figura 4: Posts do Blog que Mencionam a Biblioteca/ETS (500). Fonte: Coleta de dados com base na ferramenta analisada. 


\section{APRESENTAÇÃO E ANÁLISE DOS RESULTADOS}

A forma das fichas disponíveis no blogger é considerada prática para agregar rapidamente informações obtidas nas navegações, para armazenar diversos assuntos, tanto para o blog como para outros usos particulares, o que gerou grande número de rascunhos (Quadro 1; Figuras 1 e 3).

Verificou-se que, além das 57 biografias (Quadro 2), houve mais 76 citações a personalidades de diversas áreas, totalizando, assim, 133 nomes de pessoas ligadas a algum acontecimento marcante.

Realizando alguns cálculos (Figura 2), nota-se que as tags usadas de duas a vinte e oito vezes somam 290 (total de tags: 804-504: tags usadas apenas uma vez = 300); $(300-10$ : tags mais usadas $=290)$.

No último gráfico (Figura 3), há subsídios para um futuro direcionamento do blog: se o propósito for divulgar com mais freqüência o acervo, pode-se dar ênfase a posts específicos. Mas se for considerado que a proposta inicial de oferecer informações sobre assuntos variados e atuais consolidou-se na comunidade escolar, pode-se manter a linha editorial adotada até o momento.

A futura aplicação de pesquisa de opinião ou enquete pode ser útil para que se defina e refine o perfil do blog, mantendo-o como está ou redirecionando-o.

Salienta-se que nestes primeiros 500 posts do blog foram referenciadas 265 obras do acervo da Biblioteca da ETS, em diversos tipos de suportes físicos: livros, periódicos, enciclopédias e atlas, incorporados através de compra ou doações do Fundo Nacional para o Desenvolvimento da Educação (FNDE) e da comunidade.

Os Comentários dos 500 posts, espaços importantes de interação com o leitor, somam 144 (128: Quadro 1 + 16: Quadro 2). Dentro da comunidade escolar, constata-se que as interações foram mais reais do que virtuais. Poucos alunos, professores e funcionários deixaram seus comentários no blog, mas em conversas informais, nos intervalos de aula, na sala dos professores, corredores, biblioteca, enfim, no ambiente escolar e também nos eventos promovidos semestralmente no HCPA, houve bastante retorno, curiosidade e trocas.

$\mathrm{Na}$ figura 2, sobre os assuntos mais freqüentes postados no blog nota-se que o assunto "livros" desponta à frente, com praticamente a mesma quantidade do campeão "rascunhos"; em seguida, temos as "TICs" e, em quarto lugar, as datas comemorativas. A seguir, "bib/ETS", "vários", "acervo", e "educação". Em nono lugar, dois assuntos empatados, mas bastante semelhantes: "música" e "artes" (ambos da área cultural).

A figura 3 traz as tags utilizadas para a recuperação das informações contidas na ferramenta: é através das tags que os mecanismos de busca (como o Google) indexam os posts do blog. A seguir, as dez tags mais frequentes: "leitura", a campeã, aparece em 105 posts; "evento", em segundo lugar, em 87 posts; em terceiro, "datas comemorativas", com 79 posts diferentes, "livros" (grifo nosso), 44 posts; "Porto Alegre", 41; "arte", 38; "ETS", 37; "livro" (grifo nosso), 33; "literatura", 31 e, em décimo lugar, "comunicação", com citações em 29 posts. Não são consideradas neste gráfico as tags que aparecem com frequência entre duas e vinte e oito vezes, totalizando 290 tags diferentes. Pode-se afirmar que as tags/assuntos são bastante diversificados, 
confirmando a categoria em que este blog foi inscrito no "Prêmio Top Blog 2009": Variedades.

Quanto à diversidade dos posts do blog, Maciel (2009) observa que "o que chamou a atenção neste blog foi a variedade de assuntos abordados, geralmente relacionados com algum fato novo que estivesse na mídia, algum acontecimento na escola, ou outro fator considerado relevante." Corrobora-se as observações da autora, pois em um universo de 804 tags, 504 encaixavamse neste caso: apareciam uma única vez ao longo dos 500 posts analisados em quatorze meses.

\section{CONSIDERAÇÕES FINAIS}

O blog mostrou-se uma efetiva e poderosa ferramenta de marketing, divulgando as ações da Biblioteca da ETS e trazendo, como uma das conseqüências positivas, as parcerias construídas ao longo destes meses tanto com o Instituto Federal (IFRS) quanto com a Faculdade de Biblioteconomia e Comunicação (FABICO/UFRGS), decorrentes da existência do blog: visitas de três turmas (IFRS) com palestras sobre a ferramenta da Web 2.0 (o blog) e diversos estagiários curriculares e voluntários em suas dependências (IFRS, FABICO e ETS).

Também funcionários (secretária da ETS) e professores (do Curso Técnico em Nutrição e Dietética) estão iniciando a criação de seus blogs inspirados na ferramenta "Biblioteca ETS".

Houve, também, aulas planejadas em conjunto, contemplando a interdisciplinaridade: a bibliotecária e a professora de Sociologia, utilizando a ferramenta descrita (assunto: slogans de Maio de 68). Com a professora de Anatomia foi organizada uma exposição (Sistema Esquelético) na biblioteca, divulgada no blog. O mesmo ocorreu com a disciplina de Artes e com diversos eventos promovidos pela ETS: há divulgação no blog, proporcionando interação e visibilidade às ações realizadas pela comunidade escolar. Além disso, as autoras são solicitadas em palestras e apresentações sobre a WEB 2.0 em eventos na área de Ciência da Informação.

Todos estes resultados advindos da criação e manutenção desta ferramenta da Web 2.0 foram decisivos para a construção de uma biblioteca escolar cada vez mais interativa, atualizada, dinâmica que busca seu lugar na sociedade atual, auxiliando na promoção da inclusão digital e da cidadania. Enfim, é necessário compreender que a construção verdadeiramente humana da Rede Mundial perpassa pela formação de uma rede de afetos fundamentada na tolerância às diferenças, na colaboração mútua - trocas de saberes, vivências, experiências - e na solidariedade entre as pessoas.

\section{Notas do texto}

1 Pessoas nascidas após 1991 quando Tim Berners-Lee criou a Web no CERN, em Genebra, Suíça.

2 Disponível em: <http://oglobo.globo.com/pais/noblat>. Acesso em: 2 nov. 2009. "Ricardo Noblat manteve, neste blog, o tratamento jornalístico com o qual havia construído e consolidado, ao longo de mais de trinta anos de carreira jornalística, a credibilidade que o fez trilhar uma bem sucedida carreira como blogueiro." (ESCOBAR, 2008, p. 2). 
Ver a este respeito o blog mantido por Gutierrez. Disponível em: <http://www.gutierrez.pro.br/>. Acesso em: 23 nov. 2009.

\section{REFERÊNCIAS}

AUN, Marta Pinheiro; ANGELO, Edna da Silva. Observatório da Inclusão Digital. In: AUN, Marta Pinheiro (Coord.). Observatório da Inclusão Digital: descrição e avaliação dos indicadores adotados nos programas governamentais da infoinclusão. Belo Horizonte: Orion, 2007. Cap. 2, p. 63105.

BEHR, Ariel; MORO, Eliane Lourdes da Silva; ESTABEL, Lizandra Brasil. Gestão da biblioteca escolar: metodologias, enfoques e aplicação de ferramentas de gestão e serviços de biblioteca. IN: Revista Ciência da Informação, Brasília, v. 37, n. 2, p. 32-42, maio/ago. 2008.

COUTINHO, Kátia Soares. Biblioteca ETS, online.

Disponível em: <http://bibliotecaets.blogspot.com/>. Acesso em: set./dez. 2009.

ESCOBAR, Juliana. Blogs e Ethos Jornalístico: o que há de novo? In: CONGRESSO BRASILEIRO DE CIÊNCIAS DA COMUNICAÇÃO, 31., 2008, Natal. Intercom 2008. Disponível em: <www.ufrn.br/intercom>. Acesso em 26 jun. 2010.

FERREIRA, Aurélio Buarque de Holanda. Aurélio: o dicionário da língua portuguesa. 2. ed. Curitiba: Positivo, 2008.

LÜDKE, Menga; ANDRÉ, Marli E. D. A. Pesquisa em Educação: abordagem qualitativa. São Paulo: Ed. Pedagógica e Universitária, 1986.

MACIEL, Helena Maria Noms. A Web 2.0 e as Tecnologias de Informação e Comunicação: a construção de blogs no curso Especialização em Bibliotecas Escolares e Acessibilidade, 2009. 98 f. Trabalho de Conclusão de Curso (Graduação)-Faculdade de Biblioteconomia e Comunicação, Universidade Federal do Rio Grande do Sul. Porto Alegre, 2009.

NEVES, lara Conceição Bitencourt. Ler e Escrever na Biblioteca. In: NEVES, Iara Conceição Bitencourt et al. (Org.). Ler e Escrever: compromisso de todas as áreas. 6. ed. Porto Alegre: Ed. UFRGS, 2004. p. 219-229.

ROSA, Helaine; ISLAS, Octávio. Contribuições dos Blogs e Avanços Tecnológicos na Melhoria da Educação. In: AMARAL, Adriana; RECUERO, Raquel; MONTARDO, Sandra. (Org.). Blogs.com: estudos sobre blogs e comunicação. São Paulo: Momento, 2009. P. 161-177. Disponível em:

<http://www.sobreblogs.com.br/blogfinal.pdf>. Acesso em: 24 abr. 2010.

TOP BLOG: o maior portal de blogs da internet brasileira: Disponível em: <http://www.topblog.com.br/top.php>. Acesso em: 18 mar. 2010. 